\title{
Neuroeducational research in the design and use of a learning technology
}

Howard-Jones, P., Holmes, W., Demetriou, S., Jones, C., Tanimoto, E., Morgan, O., Perkins, D. and Davies, N., 2014. Neuroeducational research in the design and use of a learning technology. Learning, Media and Technology, 40(2), pp.1-20.

\section{Abstract}

Many have warned against a direct 'brain scan to lesson plan' approach when attempting to transfer insights from neuroscience to the classroom. Similarly, in the effective design and implementation of learning technology, a judicious interrelation of insights associated with diverse theoretical perspectives (e.g. neuroscientific, pedagogical and classroom praxis) may be required. A design-based research approach to the development of learning technology informed by neuroscience may be one way of achieving this interrelation. Accordingly, here we report on some of the preliminary research of a web app, known as 'zondle Team Play' (zTP), that allows teachers to teach whole-classes using a games-based approach and which draws on concepts from neuroscience. Recent research into the brain's reward system has provided fresh understanding about the educational potential of learning games and associated underlying cognitive and neural processes. However, the harnessing of such understanding for educational benefit presents many challenges, not least because the science potentially impacts on pedagogical theory as well as technological design, with outcomes in the classroom likely to depend on a successful interaction of both. The emergent nature of the neuroscientific concepts imbues the design process with additional uncertainties. In reporting on the design-based research of zTP, we focus on the role of lowfidelity prototyping and participant design in establishing optimal design directions likely to benefit teaching and learning. Rather than just exploring 'what works' in terms of the technology, low-fidelity prototyping and participant design helped us explore aspects of praxis and affordances of the technological design that were contingent upon each other. Five cycles of design, intervention, analysis and reflection revealed some potential benefits of a neuroeducational approach to learning technology design, including the development of related pedagogy, identification of immediate and future neuroeducational research questions and the development of language and terms suitable for communicating across interdisciplinary boundaries.

Keywords: Teaching; pedagogy; games; technology; neuroscience; rewards. 


\section{Introduction}

The development of technology for learning is one field of innovation where the new dialogue between neuroscience and education is considered closest to having positive impact (Butterworth et al. 2011; Howard-Jones et al. 2014; Royal Society 2011). However, it has been argued that the successful integration of neuroscience into educational thinking and practice requires a so-called 'neuroeducational' approach (Howard-Jones 2010) in which a trans-disciplinary collaboration between those working in education and neuroscience assures optimal outcomes in terms of scientific validity and educational relevance.

The design of educational technology potentially introduces another field of expertise and a new set of issues, requiring the integration of neuroscientific, educational and technological concepts and understanding. Here, we argue that this may best be achieved through a design-based research process involving low-fidelity prototyping and participant design, and we provide a case study of our own (the design-based research of a games-based teaching app, 'zondle Team Play') to illustrate the issues that can arise in working across these three fields (education, neuroscience and technology).

\section{Neuroeducational research and educational technology}

The last decade has seen something of a step-change in efforts to bring cognitive neuroscience and education together in dialogue. This may be due to anxieties over the 'parallel world' of pseudo-neuroscience (Geake 2008; Dekker et al. 2012; Howard-Jones et al. 2009b), but it may also be because of new insights arising from neuroscience with genuine value for education (de Jong et al. 2009; Howard-Jones 2007; Royal Society 2011; OECD 2007). Indeed, neuroscientists appear increasingly willing to speculate on the possible relevance of their work to 'real world' learning, albeit from a vantage point on its peripheries (e.g. Della Sala \& Anderson 2012). Such speculation often comes under the heading of 'educational neuroscience', a term that broadly encompasses any cognitive neuroscience with potential application in education. Accordingly, its research basis may be characterised by the epistemology, methodology and aims of cognitive neuroscience. However, moving from speculation to application is not straightforward, since the educational value of insights from neuroscience rest on their integration with knowledge from more established educational perspectives. Seeking meaningful relationships between neural processes and 
the types of complex everyday learning behaviours we can observe in classrooms presents a challenge.

One thing appears clear from the outset: a simple transmission model in which neuroscientists advise educators on their practice, or developers on their products, is unlikely to be effective. Neuroscientists are rarely experienced in considering classroom practice, and neuroscience cannot provide instant solutions for teachers. Instead, research is needed to bridge the gap between laboratory and classroom. To emphasise the key role of educational values and thinking in the design and execution of such a venture, researchers at the University of Bristol have used the term 'neuroeducational research' to describe this enterprise (Howard-Jones 2010). For both scientists and educators, co-construction of concepts requires broadening personal epistemological perspectives, understanding different meanings for terms used in their everyday language (for example: learning, meaning, attention, reward) and appreciating each other's sets of values and professional aims. This boils down to having a dialogue about how the different perspectives and their favoured types of evidence can inform about learning in different but potentially complementary ways.

In contrast to such authentic interdisciplinary work, brief intellectual liaisons between education and neuroscience are never likely to bear healthy fruit. These flirtations may, indeed, spawn further neuro-myths. A typical example of such myth-making is when synaptic connections in the brain are used to explain how we form connections between ideas. This often involves a conflation of brain and mind that allows some educational practices to gain an apparently neuroscientific flavour (research shows that explanations involving neuroscience provide greater satisfaction, even when the neuroscience is irrelevant, Weisberg et al. 2008). In reality, however, psychological theories about the mind are key to understanding the significance of brain data for behaviours such as learning; and association between ideas is a well-studied psychological concept that is currently impossible to study at the level of the synapse.

Nevertheless, having this important conversation about how different perspectives inform learning is a first step towards a theoretical framework for research at the interface of neuroscience and education. This can help us combine findings more judiciously across perspectives to develop a better understanding of learning. However, such an aspiration also 
has implications for methodology. If there is a genuine commitment to interrelate findings from component perspectives, the methods associated with these perspectives should be adapted to better support such interrelation. For example, qualitative interpretation of classroom discourse can draw usefully on neurocognitive concepts in the interpretive analysis of its meaning. Some brain imaging studies can contribute more meaningfully to the construction of neuroeducational concepts if they include semi-structured interviews of participants, to derive experiential insights about their constructs, strategies and attitudes. In some bridging studies, judicious compromise and innovative approaches may help improve the ecological validity of experimental tasks while still attempting to control extraneous variables. Perhaps most unusually, researchers in the same team may find themselves sequencing radically different methods to collect biological, experiential and social evidence as they attempt to construct answers that, collectively, help span the socialnatural science divide.

We believe that using such answers in the design of educational technology requires a similar process of integration. There is no guarantee that a useful learning principle derived in the laboratory and demonstrated in the classroom will be enhanced, or even survive, its implementation in a piece of software. To ensure the best outcome, this implementation must occur through a design process that includes potential end-users (i.e. teachers and learners) and those who possess current understanding of the principle's scientific basis and the current limits of that basis. The need to include users, particularly teachers, alongside other types of specialists in the design process, suggests a participant design process as a natural extension of the neuroeducational approach. To illustrate the advantages of this approach, we report here on the design-based research of a web app, known as zondle Team Play (zTP), that enables teachers to teach whole-classes using a games-based approach.

zTP was developed iteratively with teachers in five cycles of design, intervention, analysis and reflection. The design process involved a multidisciplinary team and drew on neuroeducational theory, teachers' insights grounded in practical classroom experiences, and well-established design expertise. We describe the process as design-based research, in which users are equal partners of the design and development team. Our approach was closest to that described by Facer and Williamson (2004) as 'informant design', in which 
teachers are seen as experts informing designers of key issues related to their experience, helping to develop early design ideas and testing prototypes in development. In this way, teachers had a critical role in shaping the design with their insights, alongside those with neuroscientific and design expertise.

\section{Towards a science of learning games}

The use of digital games and games-based approaches to support learning, especially on personal technologies such as smart phones and tablet computers, has recently gained prominence (Koutromanos \& Avraamidou 2014; Richards et al. 2013; Whitton 2014). The outcomes of much games-based learning research has been affirmative (cf. Perrotta et al. 2013). However, whether it is possible to conclude that "studies have proven empirically the efficacy of games-based learning over conventional methods" (de Freitas \& Maharg 2011, p.20) remains arguable. In fact, games-based learning remains relatively uncommon in the classroom (Kenny \& McDaniel 2011; Wastiau et al. 2009). Candidate explanations for this lack of uptake include the paucity of robust evidence of the efficacy of games-based approach to learning (Connolly et al. 2012), and the attitudes of teachers towards the use of games in classrooms (Bourgonjon et al. 2013). Alternatively, it may be due to a simple lack of individual access to appropriate technologies in many schools (Games \& Learning 2014). One potential approach to addressing this last possibility may be to employ interactive whiteboards, which are widely available in UK schools (Hennessy 2011) and which may afford a games-based approach to whole-class teaching (in distinction to the more widelyresearched games-based learning). Using interactive whiteboards may also offer teachers more direct control of the games-based approach and may, therefore, prove more acceptable (Grady et al. 2013; Jackson 2009).

Another candidate explanation for the slow establishment of games-based teaching and learning in schools may be the lack of a principled understanding of related learning processes and pedagogy. In fact, one line of evidence suggests the development of effective games-based teaching may arise from a carefully-considered interrelation of insights from diverse theoretical perspectives: games-based learning, pedagogical, classroom praxis, and neuroscientific (Howard-Jones \& Demetriou 2009). Fresh insight regarding the brain's reward system provides a rudimentary basis for understanding 'engagement' provided by games ('engagement' is in fact a complex construct beyond the scope of this paper, cf. 
Whitton 2011). Our motivation to win points in a game generates signals in the brain's reward system that are similar to those produced by our attraction to many other pleasures such as food (Koepp et al. 1998). This activity involves uptake of the neurotransmitter dopamine in the midbrain regions ('dopaminergic activity'). Primate studies show a brief dopamine 'spike' will be generated simply by the awareness that a reward will certainly be provided (Figure 1a) or when a totally unexpected one is received (Figure 1b). However, with the awareness that an uncertain reward may be provided (i.e. when uncertainty exists about whether a reward will be received or not), there is a brief spike plus an additional ramping up of dopamine until the outcome is known (Figure 1c) (Fiorillo 2003). Overall, this results in more dopamine being released for uncertain rewards (represented by the area underneath the lines in Figure 1), and this release peaks when the likelihood of receiving a reward is $50 \%$. This provides a potential neurobiological explanation for our attraction to games involving chance (Shizgal \& Arvanitogiannis 2003), and suggested the approach developed in zTP.

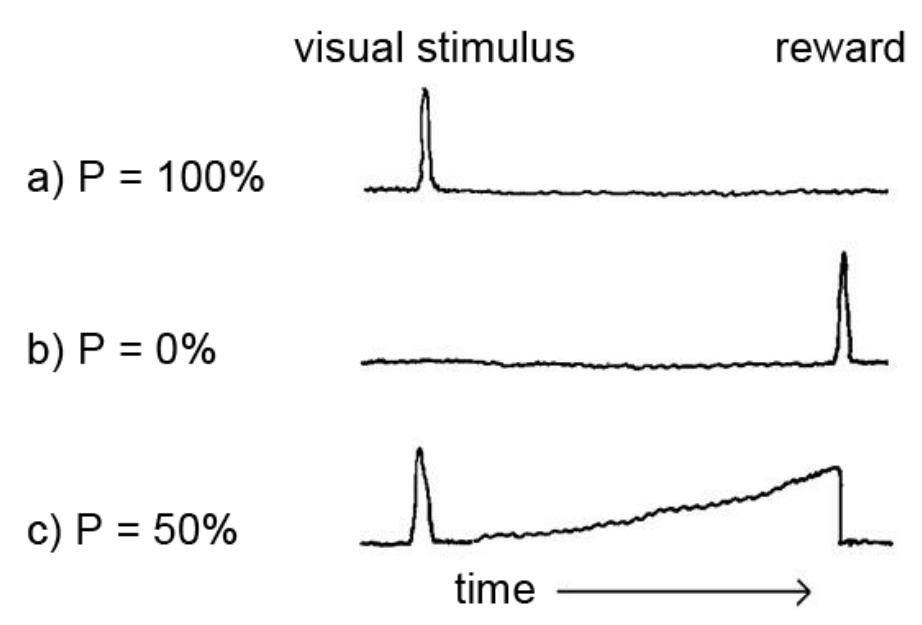

Figure 1: Uptake of the neurotransmitter dopamine generated in response to the probability $(P)$ of receiving a reward.

While humans also appear most attracted to risks involving $50 \%$ uncertainty in games, there is less attraction to this level of uncertainty when it is determined by our own ability. One study shows the level of certainty preferred by learners in purely academic tasks is around $88 \%$ (Clifford \& Chou 1991), a much higher figure which is possibly due to the implications of failure for self- and social-esteem. However, working in the comfort zone of high certainty may not fully involve the stronger motivational signals associated with the type of 
dopaminergic activity observed in games (Koepp et al. 1998; Weinstein 2010). This may also explain why emotional response during learning tasks has been found to increase when these tasks are integrated into a chance-based game (Howard-Jones \& Demetriou 2009). Given that emotional response can also support memory encoding (LaBar \& Cabeza 2006), we may also expect experiences involving more emotional response to be more memorable. Combining learning with games of chance offers a potential way of increasing reward signals and learning, without threatening esteem. There are many examples in sport and in everyday life when success arises from a combination of ability and chance, and wellmatched competition (i.e. with around $50 \%$ likelihood of outcome, such as a football game) provides a highly engaging challenge. Children, especially boys, appear to prefer the inclusion of chance-based uncertainty in learning tasks (Howard-Jones \& Demetriou 2009). Importantly for education, a positive relationship between reward activity in the brain and memory formation has also been demonstrated. In an educational game, dopaminergic activity due to gameplay rewards was estimated (based on the extent of expected gain) for each round. This signal predicted the success of memory recall more effectively than the size of the reward itself (Howard-Jones et al. 2009a).

A previous classroom study has also shown that mediating rewards for learning with chancebased events can affect the discourse around learning in positive ways (Howard-Jones \& Demetriou 2009). It tends to encourage open motivational talk and allows students to introduce a self-serving bias that attributes failure to chance (thus minimising challenges to self-esteem) and success to ability. Most recently, an independent group of researchers have extended investigations of reward uncertainty and demonstrated a clear link between increased motivation and improved learning in response to uncertain rewards (Ozcelik et al. 2013).

The following key points arise from the neuroscientific and neuroeducational research for educational practice with learning games, and comprised the starting point for the development of zTP:

- Learning games can increase student engagement through inclusion of chance-based components that increase the uncertainty of rewards for learning (Ozcelik et al. 2013). 
- The brain's response to rewards can be very brief (Bogacz et al. 2007). That suggests a close intermingling of learning and gameplay elements is needed for the gameplay to support the learning.

- Anticipation of an uncertain reward is likely to generate a more extended 'window of enhanced attention' or 'teachable moment' (Howard-Jones \& Demetriou 2009).

- Avoiding a loss does not generate the same reward signals as a gain, suggesting a generally positive scoring system may best support motivation (Howard-Jones et al. 2010).

\section{Design-based research process}

Our design team comprised of two academic researchers (who between them had experience in neuroscience research, psychology, education and games-based learning), two post-graduate assistants, teachers from two comprehensive schools in South Wales (hereinafter referred to as School A and School B), and an experienced software developer (Doug Lapsley at zondle).

The team used a design-based research approach, simultaneously pursuing practical innovation and theory building by means of the iterative development of solutions in a real world situation (Brown 1992; Cobb et al. 2003). The study did not seek to verify the hypothesised role of neural processes. Instead, it set out to build upon an understanding of those processes, as derived from studies of more controlled environments, by means of the iterative design of an intervention (a teachers' interactive whiteboard app) and its use within the real-world context of a conventional classroom. In short, the study was exploratory and developmental rather than evaluative. The science of learning games outlined above was the starting point for the first iteration of what eventually became the app known as zTP. After this, reflection on observations and outcomes in the classroom were the driving forces for developing both the further design of the app and good practice. Rather than a prescription for classroom practice, concepts about the brain provided a useful starting point for innovation and contributed to a helpful framework for stimulating reflection and understanding.

The process comprised five cycles of design, intervention, analysis and reflection (the final cycle is ongoing) and, for purposes of analytical data triangulation, involved various methods 
of data collection (observations, video recordings, interviews and group discussions, the balance between these methods evolving from cycle to cycle). In each research cycle, rather than evaluating the intervention (by comparing its effectiveness with non-gameplay approaches), we set out to identify instances of apparent learning gain as critical examples that could inform discussions and reflection about pedagogy and subsequent cycles. In the first and fourth interventions, learning gains were identified by means of a written pre- and post-test. In the second and third interventions, when we were focusing on a group with low literacy ability, we used a non-written measure. In the first four interventions, two digital video cameras (facing class and teacher) recorded the session, the video recordings being used as a basis for subsequent discussion (i.e. to stimulate recall) and group analysis. Informed consent was given by the parents of all participating students. Accumulated insights helped generate a fully-operational app for the fifth iteration, which is currently the focus of further laboratory-based studies involving neuroimaging.

\section{1 Design cycle 1}

\section{1. 1 Design}

Based on the science of learning games outlined above, the team developed a low-fidelity prototype game using Microsoft PowerPoint. The presentation comprised a repeating pattern of 1 to 2 slides of content, on the topic of 'reproduction', followed by 1 to 2 slides of multiple choice questions that assessed knowledge of this content in which each answer was labelled with one of four colours. A 'student response system' was also developed, comprising sets of four $15 \mathrm{~cm}$ square coloured cards (the same colours as those used to label the potential answers), hinged with tape, one set for each student. The final part of the design was a television quiz-style circular 'wheel of fortune', divided into coloured sectors.

\section{1.2 Intervention}

The first intervention took place in School A, with 25 students in a Year 7 science class (mean age 11 years 6 months; 13 males, 12 females), and the assessed learning objectives focused on the acquisition and recall of knowledge rather than understanding. For around ten minutes, the teacher taught an aspect of the topic 'reproduction' using the PowerPoint slides to structure and illustrate. The teacher then revealed one of the multiple-choice 
questions. To respond, the students had to choose an answer and note its colour on the PowerPoint slide, and fold their squares so that that colour faced frontwards.

This approach to using multiple-choice questions in whole-class teaching was so far conventional. However, chance-based uncertainty, as suggested by the neuroscience (Fiorillo 2003), was introduced to mediate the receipt of rewards. Each correct answer was rewarded with the option to receive a point, represented by a counter, or to take a chance and receive either zero or two points based on a spin of the 'wheel of fortune'. This became known as 'gaming the points'.

\section{1. 3 Analysis and reflection}

Throughout the session the students, particularly the boys, were observed to be engaged by this novel approach to teaching and learning: they were observed to be animated and clearly excited by the challenges, absorbed in the activity and enjoying the immediate feedback, and attending closely to the teacher's talk (Whitton 2011). However, this first session also highlighted how engagement does not necessarily translate into learning (Whitton 2014). Mean scores out of a possible 14 marks (with standard deviations in parentheses) for preand post-tests were 4.6 (2.4) and 5.8 (3.0), which represents only a modest improvement (a Wilcoxon non-parametric signed ranks test showed that this outcome was statistically significant: $z=-2.82, p=0.005, r=-0.40)$. Nevertheless, the data helped identify instances of apparent learning gain and the outcome encouraged the researchers to proceed to the next cycle of design.

All video recordings, in this and subsequent research cycles, were coded informally and iteratively by the academic team, focusing on teacher talk (for example, asking a factual question, checking understanding, motivating, praise, feedback, classroom management), student talk (centred on the question, centred on the gameplay, directed at the teacher, with other students, suggesting engagement), teacher actions (delivery of the content and game elements), and student actions (attending to the teacher, animation/excitement, attending to the game). The recordings were also used to stimulate recall in discussions with the class teachers.

The video recording from this session revealed that notable moments of heightened attention occurred when the correct answer was about to be announced and the wheel of 
fortune was turning: in other words, as the students were about to find out whether they would gain some points. However, this meant that the attention of the students was mostly on the game rather than the learning content. In addition, the teacher tended to indicate the correct answer quickly and first, such that the putative ramping up of dopaminergic activity was not being fully exploited for learning. Accordingly, it was clear that, if any engagement fostered by the gameplay was to be of educational value, greater effort would have to be made to ensure the learning content was more closely associated with the gameplay.

Nevertheless, although least successful as an intervention, a great deal was learned from this session. For example, a post- interview with the teacher confirmed that, because they needed to divide their attention between game hosting and teaching to teaching, this novel approach to teaching adding to their cognitive load rather than reducing it. Also, while the conventional scaffolding strategies remain crucial to learning (e.g. checking understanding through verbal exchanges or providing hints that focus minds on relevant content), it was clear that they can easily be forgotten in the heat of the game. If not harnessed correctly, the excitement of the game can distract students and teacher from the learning rather than help them engage with it.

In summary, this first design cycle suggested that if the approach were to be successful the teacher needed to implement three principles. They should:

a. give the students time to consider their responses before revealing the correct answer;

b. give support to help further the students' understanding of the learning content when they were answering the questions;

c. discuss potential misconceptions as the answers were being revealed (e.g. 'If this was your answer, you may have forgotten that. . '), so that those who answered incorrectly could receive additional instruction during this brief window of apparent heightened engagement.

\section{2 Design cycle 2}

\section{2. 1 Design}

In the second iteration of the design, a new topic was chosen. The content of the PowerPoint slides focused on the understanding, rather than the recall, of the grammatical 
concepts of noun, pronoun, verb and tense. Otherwise, the design was unchanged (the student response system and wheel of fortune, for example, were as before).

\section{2. 2 Intervention}

This second intervention took place in School B, involving an experienced teacher of literacy and a Year 9 group of 12 students (mean age 13 years and 7 months; 8 males and 4 females) receiving additional support for literacy. At the beginning of the session, this low-literacy group undertook a pre-test of five questions, focusing on their understanding and application (rather than their knowledge) of grammatical concepts such as noun, pronoun, verb and tense. The outcomes were later used to identify instances of apparent learning gain, with responses within the games-based session being compared with responses in the pre-test.

In most respects, delivery of the game followed the pattern of the first intervention.

However, based on the previous outcomes, in this cycle there was a greater emphasis on the educational content rather than the gameplay (with 3 to 4 slides of content followed by the 1 to 2 slides of questions). In addition, the teacher aimed to implement the principles derived from the previous design cycle.

This second intervention introduced a further development based on neuroscience research, this time around the relationship between the brain's reward response and social context. This research suggests (i) a link between midbrain dopamine uptake and the expectations generated by recent history (Schultz 1998) and (ii) that the maximum uptake is proportional to the maximum reward available in a context (Nieuwenhuis et al. 2005). Drawing on this research, in this second intervention, the teacher was encouraged to increase gradually the number of points available for each round.

\section{2. 3 Analysis and reflection}

The mean of pre-test learning scores was 53\%, and mean scores during the game (which used questions of similar type to the pre-test) was $65 \%$. Although statistical analysis was inappropriate (the sample size was small and the answering of questions was occasionally supported by the teacher), the data again helped identify instances of apparent learning gain, with a clear example of four students who failed some pre-test questions but who answered correctly similar questions during the game. The discourse that appeared to 
prompt this highlighted how the additional engagement that the game was intended to provide may be used as an opportunity to scaffold students' learning.

The video recording revealed that there were also several instances of the teacher checking understanding and praising it, and of students being supported as they were answering questions. Generally, however, the teacher was disappointed at not being able to apply consistently the three teaching principles arising from the first iteration. Although an experienced teacher, she found that the game format of the lesson made additional demands on her management and thinking processes and took up time (e.g. giving out counters and moving back and forth between whiteboard and wheel of fortune).

Nevertheless, the students were observed to be highly animated and engrossed throughout the session; with the continual raising of the stakes appearing to help maintain the students' excitement and motivation to participate (while possibly also reducing the likelihood of engagement being diminished by expectation). The increasing stakes also made the final outcome even less predictable, since later rounds had more influence on scores than earlier ones.

The chance-based outcomes also appeared to generate emotional teacher-student empathy whatever the outcome, suggesting that games-based teaching may change the emotional content of teacher-student exchanges. When outcomes arose through chance, the teacher could acknowledge failure as expressively and as strongly as success. This may make for a more authentic sharing of emotions than afforded by the conventional classroom focus on the positive. There was also, for example, some rejoicing when someone else in the class failed to win points. A recent $\mathrm{fMRI}$ study, carried out in order to provide insight into such issues, revealed that the reward response to our competitor is related to their losses (Howard-Jones et al. 2010).

\section{3 Design cycle 3}

\section{3. 1 Design}

The third iteration focused on reducing the demands on the teacher by automating part of the game (that is on classroom pragmatics rather than neuroscientific theory). A purposebuilt macro for PowerPoint was developed (Figure 2). While students still gave their responses using coloured cards, the macro allowed the teacher to record on-screen the 
students' responses to questions and their decisions whether or not to game their score. It also included an automatic flashing light version of the wheel of chance that automatically recalculated the scores. Although technology-based, we would still describe this prototype as low-fidelity, with minimal functionality and graphic quality.

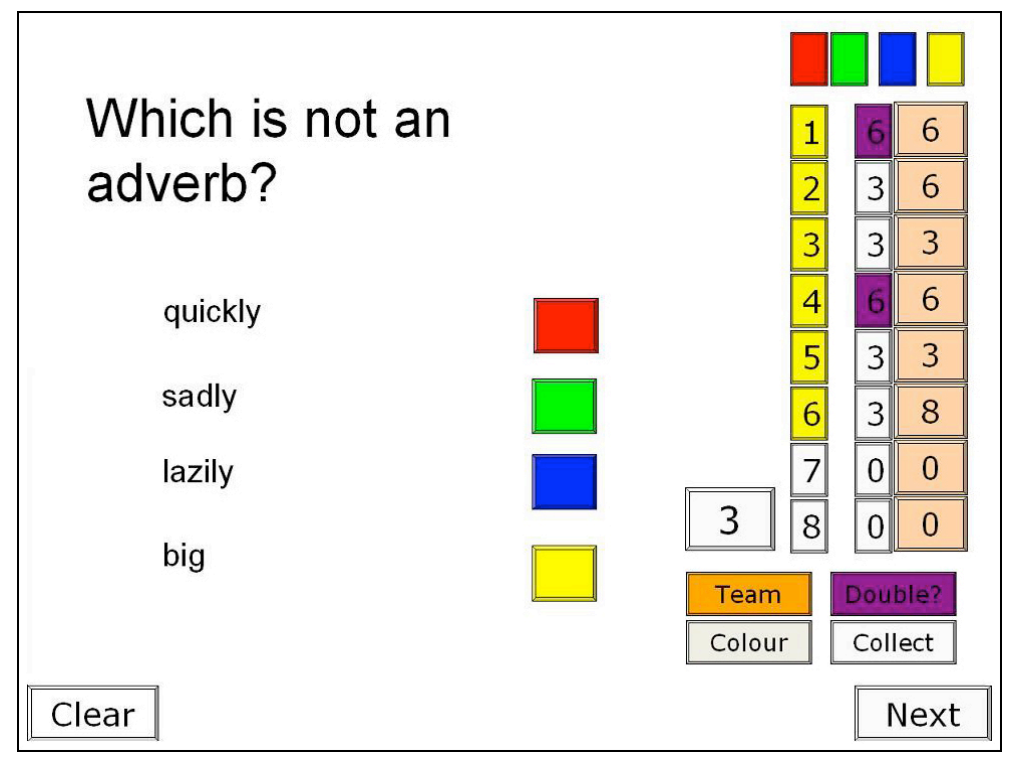

Figure 2: Screen shot of PowerPoint with additional interactivity for gameplay provided by a small macro programme.

\section{3. 2 Intervention}

The third intervention involved the same participants as the second intervention, studying another set of grammatical concepts: adjectives, adverbs, capitals and full stops in sentences, commas and speech marks. This time, however, participating students were divided into pairs and competed as six teams, in order to give an opportunity for additional collaborative and constructivist dialogue to support learning. The teacher again aimed to implement the teaching principles identified earlier, and also was encouraged to adopt a new strategy to take further advantage of the supposed ramp in dopaminergic activity (based on Fiorillo 2003): revealing the incorrect answers, and explaining why they were incorrect, before revealing the correct answer: that is to say, while the students were most attentive as they waited to find out whether or not they had been successful.

\section{3. 3 Analysis and reflection}


The mean of pre-test learning scores across teams was 39\%, while the mean scores during the game were much higher, at $80 \%$, broadly suggesting that some learning had taken place (although, for the same reasons as before, statistical analysis was again inappropriate). An important outcome of introducing a technology that removed the need to manage counters was a four-fold increase in student-teacher interactions, of which a higher proportion were related to the learning content. Initially, students responded in brief to teacher questions. After around ten minutes, exchanges grew in duration and complexity, concepts and principles were discussed, and students offered unprompted examples and asked questions to verify understanding.

In the post- interview, the teacher indicated that she was much more positive than in the previous cycle. She felt she had been able to focus more on the teaching, and was delighted with the level of engagement that she believed the game had helped create. In addition, she noted that students had shown signs of independent thinking about the principles, and that the discussion became more spontaneous as students made unprompted contributions. Meanwhile, the strategy of revealing incorrect answers before correct answers appeared to increase further the students' attention. The video recording revealed that the intense engagement was particularly evident for several students who became increasingly animated as the teacher scrutinised each incorrect option in turn, taking full advantage of these key 'teachable moments' (as suggested by the notion of dopaminergic activity) while building up the tension until the correct answer was finally revealed.

\section{4 Design cycle 4}

\section{4. 1 Design}

The fourth iteration used unaltered the PowerPoint macro (including the automatic flashing light version of the wheel of chance) and coloured cards developed in the previous cycles. A new topic area was chosen (the evaluation of plastic products).

\section{4. 2 Intervention}

The sample was a mixed-ability Year 10 Design and Technology group (in School A) comprising nine students (mean age 15 years 7 months; all males). The teacher believed, based on their knowledge of the students and their own professional experience, that the students would benefit from independent and constructivist learning opportunities. 
Accordingly, the intervention approach was slightly revised. General concepts were presented at the beginning of the lesson, without the on-screen interface, and discussed with the students. Then, working in teams of two (comprising four pairs of students and one student supported by a classroom assistant), the students used notes provided by the teacher to support discussion, knowledge construction and joint decision making. After twelve consecutive game rounds, involving the flashing light 'wheel of chance', notes were removed and the students faced another twelve rounds. Incorrect responses to the questions were used to identify potential issues with understanding and these prompted additional explanations from the teacher and teacher-student discourse to scaffold learning. This change in approach was mostly a response to the needs of the particular learning context; and its implementation drew attention to how a games-based approach to teaching, like other types of teaching, is situated in contextual issues such as group dynamics, ability, level, and topic.

A pre-and post-test required the students to choose an appropriate type of plastic with which to manufacture a specified product, by recalling and correctly applying principles discussed in the session.

\section{4. 3 Analysis and reflection}

Mean scores out of a possible five marks (with standard deviations in parentheses) for the pre-and post-tests were $1.3(0.8)$ and $3.2(1.3)$ (despite the small sample size, a Wilcoxon non-parametric signed ranks test showed that this outcome was statistically significant: $z=-$ 2.49, $p=0.013, r=-0.89)$. The difference in the mean scores represents a large effect size (Cohen's $d=2.18$ ) which, and despite the inevitable confounding variables, suggests that some learning was taking place. This was reaffirmed by the teacher, who in the postinterview argued that the students had achieved 'good' levels of understanding.

Student talk during the session included a small number of queries to the teacher, publicly expressed gameplay talk (boasting, teasing and joking) and many furtive utterances as they quietly conferred with their partner. The conferring (when it was audible in the video recording) was chiefly about learning content and gameplay strategy. Often, during these exchanges, students maintained their visual attention on the teacher and question displayed on the screen at the front of the class, as if trying to conceal their conversation from the rest of the class. When announcing answers, the teacher revealed incorrect answers first in order 
to exploit the window of attention or 'teachable moment' created by anticipation. Both quiet conferring and public exclamations indicated close attendance to this information. There were several occasions when the teacher's talk slipped into something resembling that of a television game-show host. This appeared to generate more excitement, working up the emotions of the players, sometimes gentle goading, sometimes a voice of caution or comfort.

Those who were not in the lead towards the end of the lesson took all opportunities to game their scores, as their chances to win without doing so dwindled. Other strategies included teams avoiding giving away answers by hiding their response until the last minute, by not putting it up or covering it with their bag etc. Some went as far as beginning with an answer they knew was wrong and encouraging others to see it, before changing it at the last moment to their chosen response. This prompted the researchers to consider the potential benefits of an electronic response system instead of the coloured cards. This mAY allow responses to be covert until all students had committed themselves, so preventing plagiarism. It would also reduce the time taken for responses to be collected and liberate the teacher from some of the remaining administrative tasks that teaching with the game involved, allowing the teacher to focus their attention more entirely on the teaching.

\section{5 Design cycle 5}

The fifth iteration of this games-based approach to teaching involved the collaborative design of a web app, in association with the developers of a games-based learning platform, 'zondle'. The app, known as 'zondle Team Play' (zTP, Figure 3), was itself designed iteratively: it was based on the low-fidelity versions discussed above and scaffolded by a series of conversations between this paper's lead authors and the developer. No additional neuroscientific insights were incorporated. Instead, the aim was to make the app robust, easier to use and more widely available than the low-fidelity prototypes. The alpha version of the web app was further mediated by extensive feedback from users both in the UK and from overseas (including the USA, Croatia and Australia). The app is freely available on the developers' website (www.zondle.com) and is discussed in some detail in (Howard-Jones \& Fenton 2012). 


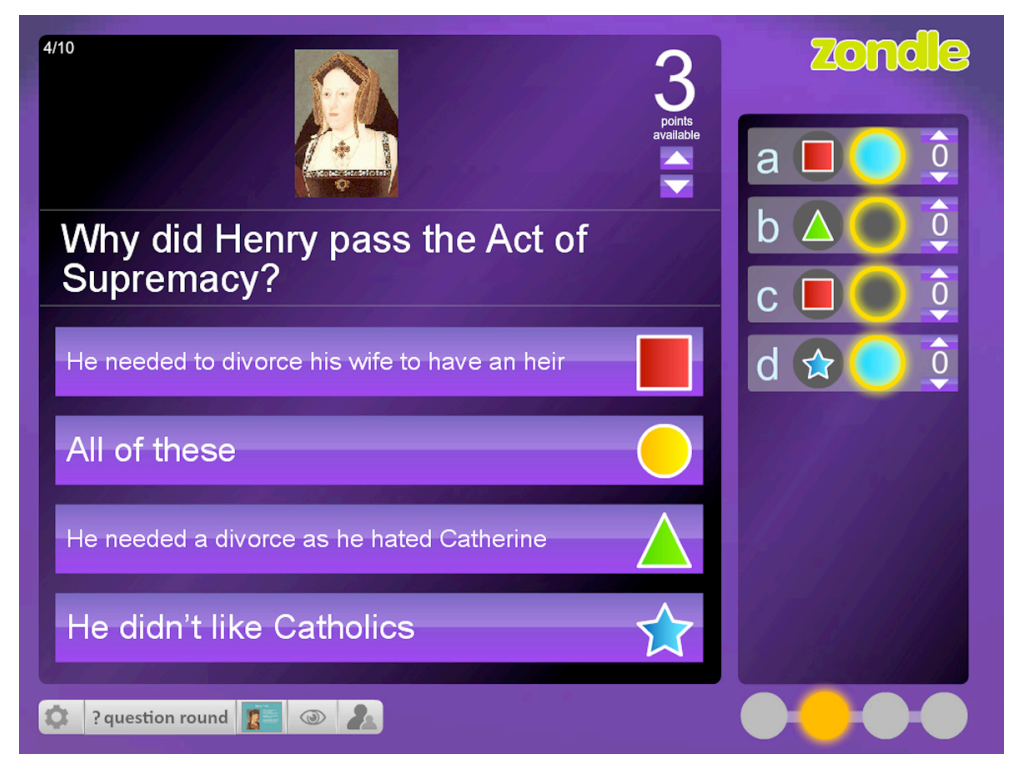

Figure 3: The main screen from the app 'zondle Team Play', showing a question about the Tudors.

ZTP was designed to be used on any interactive whiteboard (or with a computer and projector) that has Internet access. Teachers can import their PowerPoint slides into the system and can write appropriate multiple-choice questions. Alternatively, they can use and, if they choose, amend any of the more than 12,000 zTP topics written by other teachers and currently on the system. The app provides a way to allocate answers to teams, automatically allocates and records points, and includes a wheel of chance that can be started by a student swiping the interactive whiteboard. Finally, students can interact directly with the app by using any mobile device or computer with Internet access (much as if using an electronic response system), enabling students in different locations to compete in a single zTP session (for example, a class in Croatia and a class in the USA have competed in several zTP sessions, which has led to further collaboration between the schools involved).

Examples of suggestions made by teachers who used the alpha version of the app, that were incorporated into the current beta version of the app, include: showing a thumbnail of the current learning-content slide (to help orientate the teacher), the ability to switch the interface left to right (so that teachers can easily interact with it whichever side of the display that they prefer to stand), and the ability to hide answers given by the teams until all the teams have answered (to minimise teams copying each other). Anecdotal evidence for the playability, practicality and effectiveness has so far been positive: "it was insightful watching the children in different groups - listening to their thought processes and how they 
decided on their answers" (Hallybone 2012). However, zTP is currently the focus of further laboratory-based studies, including the use of neuroimaging, which will be reported later.

\section{Discussion}

\section{1 Pedagogy and classroom praxis, not just product}

The development of zTP has shown that there are potential benefits from a games-based teaching app grounded in neuroscientific research. However, it has also highlighted the importance of simultaneously developing an understanding of how such technology is best implemented, including the associated pedagogy. Such implementation and pedagogy were informed by the participants (the teacher and student experiences) but also by considering the scientific principles involved. This, perhaps, is true of other types of educational technology but in the case of novel approaches informed by neuroscience there may be a special case for ensuring trans-disciplinary construction of associated pedagogic principles, given the distance between biological and educational perspectives on learning.

Construction of pedagogical understanding was not simply important for the development and implementation of the app, but also informed its design. The implementation of our low-fidelity prototype allowed us to understand the potential importance of the teacher scaffolding learning just prior to students gaming their points through a combination of educational insight (feedback from teacher and students in the classroom) and neuroscientific understanding (in terms of the 'ramping up' of dopamine shown in Fig 1c, Fiorillo 2003). This insight influenced how incorrect answers can be revealed in the most recent ZTP version. As students were expected to be highly engaged (attentive) during this period, incorrect options disappear as the teacher touches them, allowing the teacher to provide a structured dismissal of these options as they talk through why each one is incorrect. Another example was the need for the teacher to be able to raise and lower stakes spontaneously through the game. Again, this arose through a combination of educational insight and neuroscientific understanding (in terms of effects of the points available on midbrain dopamine response, Shizgal \& Arvanitogiannis 2003). Thus, a convenient way for the teacher spontaneously to raise the stakes in each round was introduced into the design. Our process allowed pedagogy and product design to come about together and inform each other's development, supporting the potential for their optimal interrelationship in the classroom. 


\section{2 Demand push, not just technology pull}

Working with low-fidelity prototypes prevented trends in technology, the 'lure of the new', from dictating the design of the outcome. Instead, having been based on current neuroscientific understanding, this technology was then shaped by the needs and wishes of teachers and students (rather than by, for example, the capabilities of conventional audience response systems, or the immersive approach of much games-based learning).

\section{3 Translating neuroscientific principles to the classroom}

There were a large number of usability and pedagogical issues encountered during the design of ZTP (for example, how to show the next content slide to the teacher without showing it to the students, how to prevent students observing and copying each others' responses, and how to allow the teacher to work through the incorrect answers before revealing the correct answer to take advantage of the 'teachable moment'). These issues were all addressed by referring back to the original neuroscience research to inform the learning principles, the feedback of the teachers and students to confirm the pedagogy and classroom pragmatics, and the experience of the research and design team to determine the final implementation. This approach appears to have been successful, and it highlights why attempts to generate technology on the basis of sound neuroscientific learning principles are unlikely to come to fruition in the classroom without a participant approach to design.

The design-based research process described above allowed us to combine the neuroscience and educational insights, to identify and develop both an effective piece of technology and the pedagogy required to implement it. Our design process did not set out to evaluate the general educational value of principles which had been studied in the laboratory and through quasi-experimental classroom studies. Nor are we able to make claims about the efficacy of this teaching game compared with other types of teaching strategy. We do, however, claim that it emphasises the need for technology based on neuroeducational concepts to be developed using a similarly interdisciplinary approach as should be used to develop the concepts themselves.

Finally, we are pleased to report that, to date, more than 35,000 zTP sessions have been played by users from more than 30 countries worldwide. However, we should emphasise that the present and all future versions of zTP will always be limited by our current state of 
scientific knowledge, which grows daily but will always be partial. Certainly, at the time of writing, many fundamental scientific and educational questions still require further research, such as the exact mechanisms by which midbrain dopamine accelerates learning, how the games-based approach may work if used over extended periods, and how suitable it may be for different contexts (such as those involving different abilities, age groups, topics, and gender). We look forward to tackling and reporting on these and other issues in the future. 
REFERENCES

Bogacz, R., McClure, S.M., Li, J., Cohen, J.D. \& Montague, P.R., 2007. Short-term memory traces for action bias in human reinforcement learning. Brain research, 1153, pp.111-121.

Bourgonjon, J., Grove, F.D., Smet, C.D., Van Looy, J., Soetaert, R. \& Valcke, M., 2013. Acceptance of Game-Based Learning by Secondary School Teachers. Computers \& Education, 67, pp.21-35.

Brown, A.L., 1992. Design experiments: Theoretical and methodological challenges in creating complex interventions in classroom settings. Journal of the learning Sciences, 2(2), pp.141-178.

Butterworth, B., Varma, S. \& Laurillard, D., 2011. Dyscalculia: From Brain to Education. Science, 332(6033), pp.1049-1053.

Clifford, M.M. \& Chou, F.-C., 1991. Effects of Payoff and Task Context on Academic Risk Taking. Journal of Educational Psychology, 83(4), pp.499-507.

Cobb, P., Confrey, J., diSessa, A., Lehrer, R. \& Schauble, L., 2003. Design Experiments in Educational Research. Educational Researcher, 32(1), pp.913.

Connolly, T.M., Boyle, E.A., MacArthur, E., Hainey, T. \& Boyle, J., 2012. A systematic literature review of empirical evidence on computer games and serious games. Computers \& Education, 59, pp.661-686.

Dekker, S., Lee, N.C., Howard-Jones, P. \& Jolles, J., 2012. Neuromyths in education: Prevalence and predictors of misconceptions among teachers. Frontiers in psychology, $3 . \quad$ Available at: http://www.ncbi.nlm.nih.gov/pmc/articles/PMC3475349/ [Accessed June 12, 2014].

Della Sala, S. \& Anderson, M., 2012. Neuroscience in Education: The Good, the Bad and the Ugly, Oxford: OUP.

Facer, K. \& Williamson, B., 2004. Designing educational technologies with users. A handbook from Futurelab, Bristol: Futurelab.

Fiorillo, C.D., 2003. Discrete Coding of Reward Probability and Uncertainty by Dopamine Neurons. Science, 299(5614), pp.1898-1902.

De Freitas, S. \& Maharg, P., 2011. Digital Games and Learning: Modelling Learning Experiences in the Digital Age. In S. de Freitas \& P. Maharg, eds. Digital Games and Learning. London: Continuum, pp. 17-41.

Games \& Learning, 2014. Teachers Surveyed on Using Games in Class. Initial report., Available at: http://www.gamesandlearning.org/2014/06/09/teacherson-using-games-in-class/ [Accessed June 12, 2014].

Geake, J., 2008. Neuromythologies in education. Educational Research, 50(2), pp.123-133.

Grady, S.E., Vest, K.M. \& Todd, T.J., 2013. Student attitudes toward the use of games to promote learning in the large classroom setting. Currents in Pharmacy Teaching and Learning.

Hallybone, D., 2012. Zondle Team Play. From Dawn till Dusk - Games and life | Musings on ICT, handhelds, learning and life. Available at: http://hallyd.edublogs.org/2012/07/17/zondle-team-play/ [Accessed June 15, 2014].

Hennessy, S., 2011. The role of digital artefacts on the interactive whiteboard in supporting classroom dialogue. Journal of Computer Assisted Learning, 27(6), pp.463-489. 
Howard-Jones, P., 2010. Introducing Neuroeducational Research: Neuroscience, Education and the Brain from Contexts to Practice, Abingdon: Routledge.

Howard-Jones, P., 2007. Neuroscience and education: Issues and opportunities, London: Teaching and Learning Research Programme. ESRC.

Howard-Jones, P. \& Demetriou, S., 2009. Uncertainty and engagement with learning games. Instructional Science, 37(6), pp.519-536.

Howard-Jones, P. \& Fenton, K., 2012. The Handbook of Teaching with Gaming,

Howard-Jones, P., Ott, M., van Leeuwen, T. \& De Smedt, B., 2014. The potential relevance of cognitive neuroscience for the development and use of technology-enhanced learning. Learning, Media and Technology, pp.1-21.

Howard-Jones, P.A., Bogacz, R., Demetriou, S., Leonards, U. \& Yoo, J., 2009a. From gaming to learning: A reward-based model of decision-making predicts declarative memory performance in a learning game. In British Psychological Society Annual Conference, 2009. Brighton.

Howard-Jones, P.A., Bogacz, R., Yoo, J.H., Leonards, U. \& Demetriou, S., 2010. The neural mechanisms of learning from competitors. Neurolmage, 53(2), pp.790799.

Howard-Jones, P.A., Franey, L., Mashmoushi, R. \& Liao, Y.-C., 2009b. The neuroscience literacy of trainee teachers. In British Educational Research Association Annual Conference. Universtiy of Manchester.

Jackson, J., 2009. Game - based teaching: what educators can learn from videogames. Teaching Education, 20(3), pp.291-304.

De Jong, T., Gog, T. \& Jenks, K., 2009. Explorations in Learning and the Brain: On the Potential of Cognitive Neuroscience for Educational Science, New York: Springer.

Kenny, R.F. \& McDaniel, R., 2011. The role teachers' expectations and value assessments of video games play in their adopting and integrating them into their classrooms. British Journal of Educational Technology, 42(2), pp.197213.

Koepp, M.J., Gunn, R.N., Lawrence, A.D., Cunningham, V.J., Dagher, A., Jones, T., Brooks, D.J., Bench, C.J. \& Grasby, P.M., 1998. Evidence for striatal dopamine release during a video game. Nature, 393(6682), pp.266-268.

Koutromanos, G. \& Avraamidou, L., 2014. The use of mobile games in formal and informal learning environments: a review of the literature. Educational Media International, 51(1), pp.49-65.

LaBar, K.S. \& Cabeza, R., 2006. Cognitive neuroscience of emotional memory. Nature Reviews Neuroscience, 7(1), pp.54-64.

Nieuwenhuis, S., Heslenfeld, D.J., Alting von Geusau, N.J., Mars, R.B., Holroyd, C.B. \& Yeung, N., 2005. Activity in human reward-sensitive brain areas is strongly context dependent. Neurolmage, 25(4), pp.1302-1309.

OECD, 2007. Understanding the Brain: The Birth of a Learning Science, Paris: Centre for Educational Research and Innovation.

Ozcelik, E., Cagiltay, N.E. \& Ozcelik, N.S., 2013. The effect of uncertainty on learning in game-like environments. Computers \& Education, 67, pp.12-20.

Perrotta, C., Featherstone, G., Aston, H. \& Houghton, E., 2013. Game-based learning: latest evidence and future directions, Slough: NFER.

Richards, J., Stebbins, L. \& Moellering, K., 2013. Games for a digital age: K-12 market map and investment analysis, New York: The Joan Ganz Cooney Center at Sesame Workshop. 
Royal Society, 2011. Brain Waves 2: Neuroscience implications for education and lifelong learning., London: Royal Society.

Schultz, W., 1998. Predictive reward signal of dopamine neurons. Journal of neurophysiology, 80(1), pp.1-27.

Shizgal, P. \& Arvanitogiannis, A., 2003. Gambling on Dopamine. Science, 299(5614), pp.1856-1858.

Wastiau, P., Kearney, C. \& Van den Berghe, W., 2009. How are digital games used in schools? Complete results of the study. Final report., Brussels: European Schoolnet, EUN Partnership AISBL. Available at: http://games.eun.org/upload/gis-full_report_en.pdf [Accessed May 16, 2010].

Weinstein, A.M., 2010. Computer and Video Game Addiction-A Comparison between Game Users and Non-Game Users. The American Journal of Drug and Alcohol Abuse, 36(5), pp.268-276.

Weisberg, D.S., Keil, F.C., Goodstein, J., Rawson, E. \& Gray, J.R., 2008. The seductive allure of neuroscience explanations. Journal of cognitive neuroscience, 20(3), pp.470-477.

Whitton, N., 2014. Digital Games and Learning: Research and Theory, London: Routledge.

Whitton, N., 2011. Game Engagement Theory and Adult Learning. Simulation \& Gaming, 42(5), pp.596-609. 